American Journal of Applied Sciences 4 (5): 323-327, 2007

ISSN 1546-9239

(C) 2007 Science Publications

\title{
Structural Analysis of Borotellurite Glass
}

\author{
Halimah M.K., Daud W.M., Sidek H.A.A., Zainal A.S., Zainul A.H. and Jumiah H. \\ Ultrasonic Laboratory, Department of Physics, Faculty of Science, University Putra Malaysia \\ 43400 Serdang, Selangor, Malaysia
}

\begin{abstract}
The average cross-link density, number of the network bonds per unit volume, average stretching force constant, atomic ring size and the ratio $\mathrm{K}_{\mathrm{bc}} / \mathrm{K}_{\mathrm{e}}$ have been calculated and discussed according to bond compression model for borotellurite glass. The result showed that the connectivity and rigidity of the borotellurite glasses increases with $\mathrm{TeO}_{2}$ content due to the transformation of $\mathrm{BO}_{3}$ units to $\mathrm{BO}_{4}$ and $\mathrm{TeO}_{3}$ units to $\mathrm{TeO}_{4}$. Comparison between theoretical calculated and experimental elastic moduli and Poisson's ratio has been carried out. The results showed good agreement between experimental and theoretical calculated elastic moduli.
\end{abstract}

Key words: Borotellurite glass, bond compression model

\section{INTRODUCTION}

Tellurite glasses with the unique physical properties and applications were reported by ElMallawany ${ }^{[1]}$. Elastic properties are very informative about the structure of solids and are directly related to the interatomic potentials. Elastic properties also provide the information about internal arrangement of the constituent oxides and the mechanical strength of the glass. Elastic moduli of tellurite, binary transition tellurite, rare earth tellurite and multicomponent tellurite glasses including halide, hydrostatic and uniaxial pressure dependencies of ultrasonic waves in these glasses at room temperature have been measured and reported ${ }^{[1]}$. Recently, elastic properties of $\left(\mathrm{TeO}_{2}\right)_{50^{-}}$ $\left(\mathrm{V}_{2} \mathrm{O}_{5}\right)_{50-\mathrm{x}}\left(\mathrm{TiO}_{2}\right)_{\mathrm{x}}$ glasses using pulse-echo technique have been studied ${ }^{[2]}$.

$\mathrm{TeO}_{2}$ and $\mathrm{B}_{2} \mathrm{O}_{3}$ are known as glass forming oxides. The structure of tellurite glass is a laminar network based on triangular $\mathrm{TeO}_{3}$ pyramids or square $\mathrm{TeO}_{4}$ pyramids ${ }^{[3]}$. Boron oxide $\mathrm{B}_{2} \mathrm{O}_{3}$ in its glassy form is a laminar network consisting of boron atoms 3-fold coordinated with oxygen which can form six-membered boroxol rings $\left(\mathrm{B}_{3} \mathrm{O}_{6}\right)$, as reported earlier by Krogh$\mathrm{Moe}^{[4]}$. When an alkali oxide modifies the pure boron oxide, the additional oxygen causes a conversion from the trigonal boron atoms $\mathrm{BO}_{3}$ into 4-fold $\mathrm{BO}_{4}$ coordinated boron atoms. Each $\mathrm{BO}_{4}$ structural group is negatively charged and the four oxygens are included in the network as bridging oxygen. These units are responsible for the increase in the connectivity of the glass network. As a result, the degree of the structural compactness and modification of the geometrical configuration in the glass network can vary with a change in the composition ${ }^{[4,5]}$. In borotellurite glasses, the $\mathrm{TeO}_{4}$ units and $\mathrm{BO}_{4}$ units have a strong tendency to link with each other to form $\mathrm{BTeO}_{3,5}$ units, which results in a higher connectivity in the glass network just like $\mathrm{BPO}_{4}$ units in borophosphate glasses ${ }^{[6]}$. In this article the elastic moduli of borotellurite glasses will be discussed. Information about the structure of the glass can be deduced by calculating the number of network bonds per unit volume, the average stretching force constant, the average ring size and the average crosslink density. The theoretical values of ultrasonic activation energy and elastic moduli are calculated and compared with the corresponding experimental values.

\section{MATERIALS AND METHODS}

For the present studies, a binary $\mathrm{TeO}_{2}-\mathrm{B}_{2} \mathrm{O}_{3}$ glass system was prepared with different mol percent $\mathrm{TeO}_{2}$. The binary $\mathrm{TeO}_{2}-\mathrm{B}_{2} \mathrm{O}_{3}$ glasses were synthesized by the method mentioned elsewhere ${ }^{[7]}$. The prepared samples were cut into required dimension for ultrasonic velocity measurement. For ultrasonic velocity measurement of the glass sample, MATEC MBS 8000 was used. All measurements were taken at $5 \mathrm{MHz}$ frequency and at room temperature. The density of the glasses was determined by Archimedes method with acetone as buoyant liquid.

Theory: For a three dimensional one component oxide glass of $\mathrm{A}-\mathrm{O}$ bond $(\mathrm{A}=$ cation, $\mathrm{O}=$ oxygen $)$, the bulk modulus $\left(\mathrm{K}_{\mathrm{bc}}\right)$ according to the bond compression model $^{[8]}$ is given by equation

$\mathrm{K}_{\mathrm{bc}}=\frac{\mathrm{n}_{\mathrm{b}} \overline{\mathrm{f}}}{9} \mathrm{r}^{2}$

where $r$ is the bond length between cation and anion, $\overline{\mathrm{f}}$ is the average stretching force constant and $\mathrm{n}_{\mathrm{b}}$ is the number of network bond per unit volume of the glass is given by

Corresponding Author: Halimah M.K., Ultrasonic Laboratory, Department of Physics, Faculty of Science University Putra Malaysia, 43400 Serdang, Selangor, Malaysia 


$$
\mathrm{n}_{\mathrm{b}}=\mathrm{N}_{\mathrm{a}} \frac{\mathrm{n}_{\mathrm{f}}}{\mathrm{V}_{\mathrm{m}}}
$$

where $N_{a}$ is Avogadro's number, $n_{f}$ is the number of network bonds per unit glass formula and $V_{m}$ is the molar volume. The stretching force constant $\overline{\mathrm{f}}$ can be calculated from the equation given by Higazy and Bridge $^{[9]}$.

$\overline{\mathrm{f}}=\frac{17}{\mathrm{r}^{3}}$

For a three-dimensional polycomponent oxide glasses, $\mathrm{K}_{\mathrm{bc}}$ and $\mathrm{n}_{\mathrm{b}}$ are given by

$$
\begin{aligned}
& \mathrm{K}_{\mathrm{bc}}=\frac{\mathrm{N}_{\mathrm{a}}}{9 \mathrm{~V}_{\mathrm{m}}} \sum_{\mathrm{i}}\left(\mathrm{x} \mathrm{n}_{\mathrm{f}} \overline{\mathrm{fr}}^{2}\right)_{\mathrm{i}} \\
& \mathrm{n}_{\mathrm{b}}=\sum_{\mathrm{i}} \frac{\mathrm{N}_{\mathrm{a}}\left(\mathrm{x} \mathrm{n}_{\mathrm{f}}\right)_{\mathrm{i}}}{\mathrm{V}_{\mathrm{m}}} \\
& =\frac{\mathrm{N}_{\mathrm{a}}}{\mathrm{V}_{\mathrm{m}}} \sum_{\mathrm{i}}\left(\mathrm{x} \mathrm{n}_{\mathrm{f}}\right)_{\mathrm{i}}
\end{aligned}
$$

where $\mathrm{x}$ is the mole fraction of the component oxide $\mathrm{i}$.

The theoretical Poisson's ratio for the polycomponent oxide glasses according to the bond compression model ${ }^{[8]}$ is given by

$$
\sigma_{\text {cal }}=0.28\left(\overline{\mathrm{n}_{\mathrm{c}}}\right)^{-0.25}
$$

where $\overline{n_{c}}$ is the average cross-link density of the glass network and is given by

$$
\overline{\mathrm{n}_{\mathrm{c}}}=\frac{1}{\eta} \sum_{\mathrm{i}}\left(\mathrm{n}_{\mathrm{c}}\right)\left(\mathrm{N}_{\mathrm{c}}\right)
$$

where $n_{c}$ is the number of cross-link per cation (number of bridging bonds per cation minus two) in oxide i. $\mathrm{N}_{\mathrm{c}}$ is the number of cation per glass formula unit and $\eta=\sum_{\mathrm{i}}\left(\mathrm{N}_{\mathrm{c}}\right)_{\mathrm{i}}$ is the total number of cations per glass formula unit.

The average atomic ring size $(l)$ of a structure consisting of a three-dimensional network according to the ring deformatiom mode ${ }^{[10]}$ is expressed in the form

$$
\mathrm{K}_{\mathrm{e}}=\frac{0.0106 \mathrm{~F}_{\mathrm{b}}}{l^{3.84}}
$$

where $F_{b}$ is the bond bending force constant which to a first approximation may be taken as proportional to the stretching force constant $\overline{\mathrm{F}}$ and $\mathrm{K}_{\mathrm{e}}$ is the experimental bulk modulus. The stretching force constant $\overline{\mathrm{F}}$ for a three-dimensional polycomponent oxide glasses is given as

$$
F=\frac{\sum\left(\mathrm{x} \mathrm{n}_{\mathrm{f}} \overline{\mathrm{f}}\right)_{\mathrm{i}}}{\sum_{\mathrm{i}}\left(\mathrm{x} \mathrm{n}_{\mathrm{f}}\right)_{\mathrm{i}}}
$$

Bridge and Patel $^{[11]}$ proposed a quantitative empirical equation to correlate between activation energy $\mathrm{V}$ of ultrasonic relaxation and the most important structure of the network that is force constant $\overline{\mathrm{F}}$ and atomic ring size $l$.

Abd. Moneim ${ }^{[12]}$ reported the following relationship after using the data of pure tellurite, tricomponent tellurite $\mathrm{TeO}_{2}-\mathrm{V}_{2} \mathrm{O}_{3}-\mathrm{Sm}_{2} \mathrm{O}_{3}$ glasses and the data of glasses used in Bridge and Patel analysis

$\mathrm{V}_{\text {cal }}=113 \overline{\mathrm{F}} l^{2.6422}$

and

$\mathrm{K}_{\text {cal }} \mathrm{V}_{\text {cal }}=1.2 \times 10^{-27} \overline{\mathrm{F}}^{2} l^{-1.36}$

These expression gave the values of activation energy in Joule and bulk modulus in GPa when unit of $\overline{\mathrm{F}}$ is $\mathrm{N} / \mathrm{m}$ and $l$ is meter.

The other elastic moduli can be obtained from bulk modulus and Poisson's ratio ${ }^{[1]}$ for each glass system as: Shear modulus

$\mathrm{G}_{\mathrm{cal}}=1.5 \mathrm{~K}_{\mathrm{cal}}\left[\frac{\left(1-2 \sigma_{\mathrm{cal}}\right)}{\left(1+\sigma_{\text {cal }}\right)}\right]$

Longitudinal modulus

$\mathrm{L}_{\text {cal }}=\mathrm{K}_{\text {cal }}+1.33 \mathrm{G}_{\text {cal }}$

Young's modulus

$\mathrm{E}_{\mathrm{cal}}=2\left(1+\sigma_{\mathrm{cal}}\right) \mathrm{G}_{\mathrm{cal}}$

\section{RESULTS AND DISCUSSION}

Table 1: Parameter adopted from the crystal structure of oxide ${ }^{[18]}$

\begin{tabular}{lllll}
\hline Oxide & $\mathrm{r}(\mathrm{nm})$ & $\mathrm{F}(\mathrm{N} / \mathrm{m})$ & $\mathrm{n}_{\mathrm{f}}$ & $\mathrm{n}_{\mathrm{c}}$ \\
$\mathrm{TeO}_{2}$ & 0.1990 & 216 & 4 & 2 \\
$\mathrm{~B}_{2} \mathrm{O}_{3}$ & 0.1380 & 660 & 3 & 1 \\
\hline
\end{tabular}

Parameters adopted from the crystal structure of each oxide are listed in Table 1. These parameters are used to calculate the number of network bond per unit volume $\mathrm{n}_{\mathrm{b}}$, bond compression bulk modulus $\mathrm{K}_{\mathrm{bc}}$, calculated Poisson's ratio $\sigma_{\text {cal, }}$ average cross-link density $\overline{\mathrm{n}}_{\mathrm{c}}$, atomic ring size $l$, the average stretching force constant $\overline{\mathrm{F}}$ and the ratio between bond compression and experimental bulk modulus $\mathrm{K}_{\mathrm{bc}} / \mathrm{K}_{\mathrm{e}}$. Table 2 lists the calculated parameters and experimental values of bulk modulus $K_{e}$, density $\rho$ and molar volume $\mathrm{V}_{\mathrm{m}}$. of $\left(\mathrm{TeO}_{2}\right)_{\mathrm{x}}\left(\mathrm{B}_{2} \mathrm{O}_{3}\right)_{1-\mathrm{x}}$ glass system. The experimental data have been taken from elsewhere ${ }^{[7]}$.

Figure 1 shows the variation of the average crosslink density $\overline{\mathrm{n}}_{\mathrm{c}}$ with $\mathrm{TeO}_{2}$ content. The average crosslink density increases as the tellurite oxide increases. The value of average cross-link density, $\overline{\mathrm{n}}_{\mathrm{c}}$ changes from 1.43 to 1.67 . The increase in the cross-link density is related to the replacement of the boron atoms with coordination number $\mathrm{n}_{\mathrm{f}}=3$ and cross-link density per cation $\mathrm{n}_{\mathrm{c}}=1$, by the tellurium atoms with higher coordination number $\mathrm{n}_{\mathrm{f}}=4$ and cross-link density per cation $n_{c}=2$. Figure 2 shows the number of network 


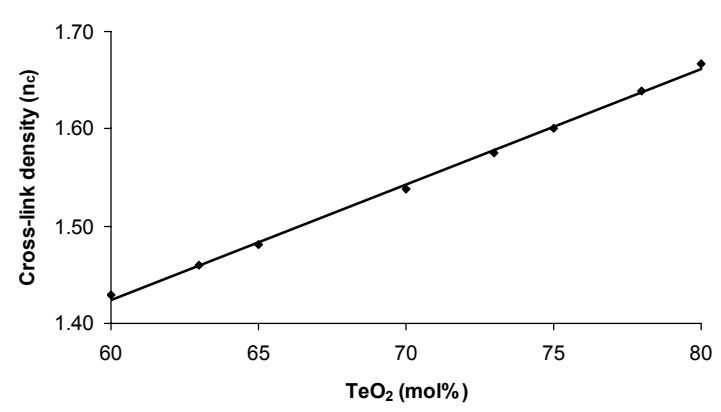

Fig. 1: Variation of the average cross-link density with $\mathrm{TeO}_{2}$ content for $\mathrm{TeO}_{2}-\mathrm{B}_{2} \mathrm{O}_{3}$ glass system

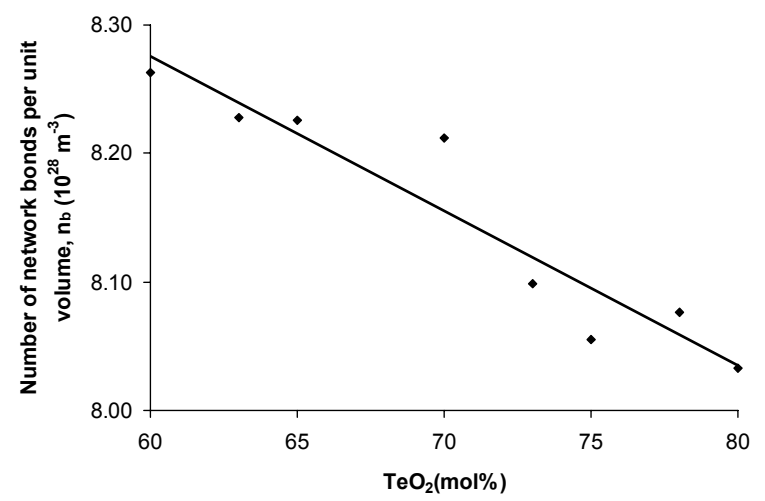

Fig. 2: Variation of the number of network bonds per unit volume with $\mathrm{TeO}_{2}$ content for $\mathrm{TeO}_{2}-\mathrm{B}_{2} \mathrm{O}_{3}$ glass system

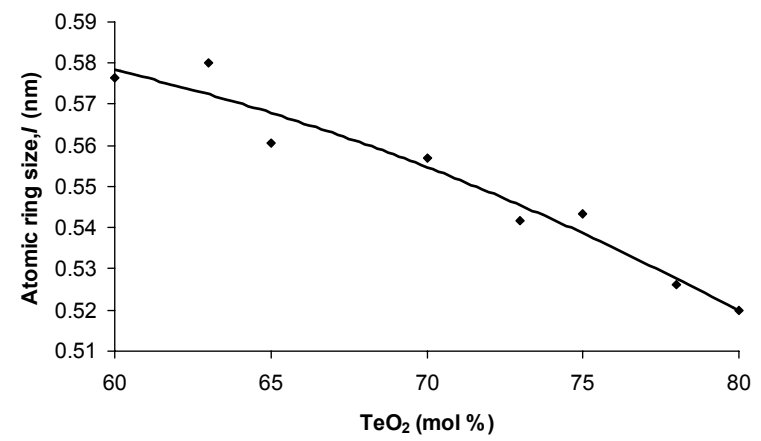

Fig. 3: Variation of the atomic ring size with $\mathrm{TeO}_{2}$ content for $\mathrm{TeO}_{2}-\mathrm{B}_{2} \mathrm{O}_{3}$ glass system

bonds per unit volume $\mathrm{n}_{\mathrm{b}}$ decreases with $\mathrm{TeO}_{2}$ content. The value of $\mathrm{n}_{\mathrm{b}}$ changes form $8.26 \times 10^{28} \mathrm{~m}^{-3}$ to $8.03 \mathrm{x}$ $10^{28} \mathrm{~m}^{-3}$. The decrease in the number of network bonds per unit volume is due to the increase in the cross-link density and the increase of molar volume with increasing $\mathrm{TeO}_{2}$ content.

The variation of the atomic ring size $l$ with $\mathrm{TeO}_{2}$ content is shown in Fig. 3. The atomic ring size of $\left(\mathrm{TeO}_{2}\right)_{\mathrm{x}}\left(\mathrm{B}_{2} \mathrm{O}_{3}\right)_{1-\mathrm{x}}$ glass decreases as $\mathrm{TeO}_{2}$ content increases. This shows that the network of the glasses become rigid with the increase of tellurium dioxide. The decreased in atomic ring size is from 0.5765 to 0.5377 with increasing $\mathrm{TeO}_{2}$ is due to the increase in

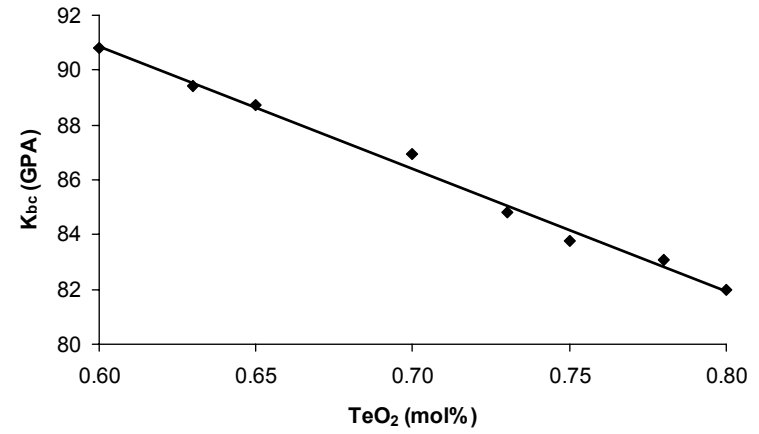

Fig. 4: Dependence of the bond compression bulk modulus with $\mathrm{TeO}_{2}$ content for $\mathrm{TeO}_{2} \mathrm{~B}_{2} \mathrm{O}_{3}$ glass system

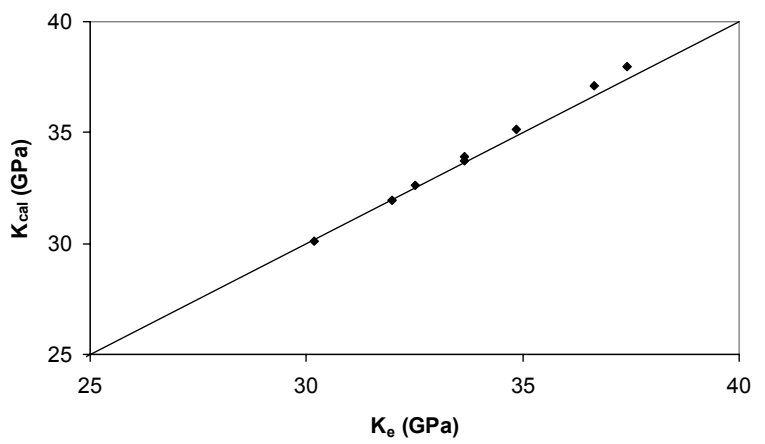

Fig. 5: Correlation between calculated and experimental bulk modulus for $\left.\mathrm{TeO}_{2}\right)_{\mathrm{x}}\left(\mathrm{B}_{2} \mathrm{O}_{3}\right)_{1 \text { - }}$. $x$ glass system

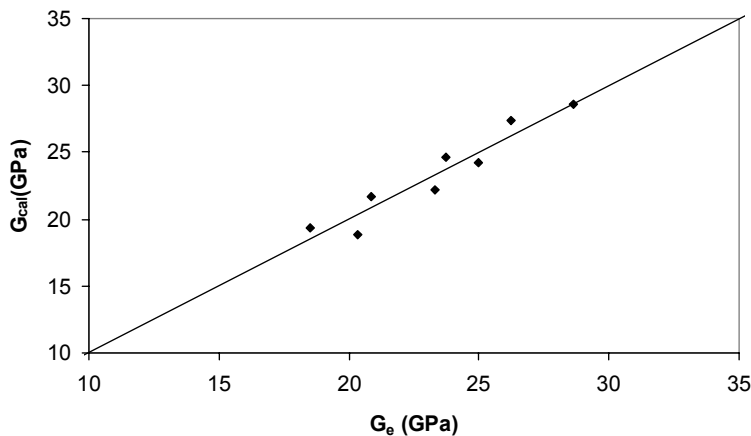

Fig. 6: Correlation between calculated and experimental shear modulus for $\left(\mathrm{TeO}_{2}\right)_{\mathrm{x}}\left(\mathrm{B}_{2} \mathrm{O}_{3}\right)_{1-\mathrm{x}}$ glass system

the number in the average cross-link density and the decrease in the number of network bonds per unit volume of the glass. The decrease in the number of network bond per unit volume $\mathrm{n}_{\mathrm{b}}$ leads to a decrease in the bond compression bulk modulus $\mathrm{K}_{\mathrm{bc}}$ as seen in Fig. 4. From the figure shows that as the number of network bonds per unit volume $\mathrm{n}_{b}$ decreases and this leads to $\mathrm{a}$ change in the bond compression bulk modulus $\mathrm{K}_{\mathrm{bc}}$ values congruent with a change in ring diameter. It can be seen that the calculated $\mathrm{K}_{\mathrm{bc}}$ depend on the mole fraction of the participant oxides, density of the glass and the molecular weight of glass. As $\mathrm{TeO}_{2}$ content increases the value of the ring diameter and the ratio 
Table 2: The calculated value of the average stretching force constant $\overline{\mathrm{F}}$, number of network bonds per unit volume $\mathrm{n}_{\mathrm{b}}$, bond compression bulk modulus $\mathrm{K}_{\mathrm{bc}}$, average cross-link density $\overline{\mathrm{n}_{\mathrm{c}}}$, atomic ring size $l$, the ratio of bond compression bulk modulus and experimental bulk modulus $\mathrm{K}_{\mathrm{bc}} / \mathrm{K}_{\mathrm{e}}$ for $\left(\mathrm{TeO}_{2}\right)_{\mathrm{x}}\left(\mathrm{B}_{2} \mathrm{O}_{3}\right)_{1-\mathrm{x}}$ glass system

\begin{tabular}{|c|c|c|c|c|c|c|c|c|c|}
\hline $\mathrm{X} \mathrm{mol} \%$ & $\begin{array}{l}\rho[\mathrm{x}] \\
\left(\mathrm{g} / \mathrm{cm}^{3}\right)\end{array}$ & $\begin{array}{l}\mathrm{V}_{\mathrm{m}} \\
\left(\mathrm{cm}^{3}\right)\end{array}$ & $\begin{array}{l}\mathrm{K}_{\mathrm{e}}[7] \\
(\mathrm{GPa})\end{array}$ & $\begin{array}{l}\overline{\mathrm{F}} \\
(\mathrm{N} / \mathrm{m})\end{array}$ & $\begin{array}{l}l \\
(\mathrm{~nm})\end{array}$ & $\begin{array}{l}\mathrm{n}_{\mathrm{b}} \\
\left(10^{28} \mathrm{~m}^{-3}\right)\end{array}$ & $\overline{\overline{n_{c}}}$ & $\begin{array}{l}\mathrm{K}_{\mathrm{bc}} \\
(\mathrm{GPa})\end{array}$ & $\mathrm{K}_{\mathrm{bc}} / \mathrm{K}_{\mathrm{e}}$ \\
\hline 60 & 4.71 & 28.24 & 31.98 & 364 & 0.5765 & 82.63 & 1.43 & 90.82 & 2.84 \\
\hline 63 & 4.75 & 26.57 & 30.17 & 352 & 0.5801 & 82.28 & 1.46 & 89.43 & 2.96 \\
\hline 65 & 4.79 & 26.72 & 33.66 & 344 & 0.5604 & 82.26 & 1.48 & 88.74 & 2.64 \\
\hline 70 & 4.89 & 27.13 & 32.51 & 324 & 0.5569 & 82.12 & 1.54 & 86.96 & 2.68 \\
\hline 73 & 4.88 & 27.74 & 34.84 & 312 & 0.5418 & 80.99 & 1.58 & 84.82 & 2.43 \\
\hline 75 & 4.89 & 28.04 & 33.64 & 305 & 0.5432 & 80.55 & 1.60 & 83.74 & 2.49 \\
\hline 78 & 4.96 & 28.19 & 36.64 & 294 & 0.5261 & 80.77 & 1.64 & 83.05 & 2.27 \\
\hline 80 & 4.97 & 28.50 & 37.42 & 286 & 0.5198 & 80.32 & 1.67 & 82.00 & 2.19 \\
\hline
\end{tabular}

Table 3: Theoretically calculated and experimental elastic moduli for $\left(\mathrm{TeO}_{2}\right)_{\mathrm{x}}\left(\mathrm{B}_{2} \mathrm{O}_{3}\right)_{1-\mathrm{x}}$ glass system

\begin{tabular}{|c|c|c|c|c|c|c|c|c|c|c|c|}
\hline $\begin{array}{l}\mathrm{X} \\
\mathrm{mol} \%\end{array}$ & $\begin{array}{l}\mathrm{K}_{\mathrm{e}}[7] \\
(\mathrm{GPa})\end{array}$ & $\begin{array}{l}\mathrm{G}_{\mathrm{e}}[7] \\
(\mathrm{GPa})\end{array}$ & $\begin{array}{l}\mathrm{L}_{\mathrm{e}}[7] \\
(\mathrm{GPa})\end{array}$ & $\begin{array}{l}\mathrm{E}_{\mathrm{e}}[7] \\
(\mathrm{GPa})\end{array}$ & $\sigma_{\mathrm{e}}[7]$ & $\begin{array}{l}V_{\text {cal }} \\
(\mathrm{eV})\end{array}$ & $\begin{array}{l}\mathrm{K}_{\mathrm{cal}} \\
(\mathrm{GPa})\end{array}$ & $\begin{array}{l}\mathrm{G}_{\mathrm{cal}} \\
(\mathrm{GPa})\end{array}$ & $\begin{array}{l}\mathrm{L}_{\mathrm{cal}} \\
(\mathrm{GPa})\end{array}$ & $\begin{array}{l}\mathrm{E}_{\mathrm{cal}} \\
(\mathrm{GPa})\end{array}$ & $\sigma_{\mathrm{cal}}$ \\
\hline 60 & 31.98 & 18.49 & 56.63 & 46.50 & 0.2576 & 0.099 & 31.93 & 19.31 & 57.42 & 48.17 & 0.2489 \\
\hline 63 & 30.17 & 20.33 & 57.28 & 49.80 & 0.2248 & 0.097 & 30.09 & 18.87 & 55.00 & 46.77 & 0.2478 \\
\hline 65 & 33.66 & 20.86 & 61.48 & 51.87 & 0.2432 & 0.087 & 33.73 & 21.67 & 62.36 & 53.48 & 0.2471 \\
\hline 70 & 32.51 & 23.33 & 63.62 & 56.48 & 0.2104 & 0.081 & 32.63 & 22.15 & 61.88 & 54.13 & 0.2452 \\
\hline 73 & 34.84 & 23.74 & 66.49 & 58.03 & 0.2224 & 0.073 & 35.12 & 24.62 & 67.63 & 59.80 & 0.2441 \\
\hline 75 & 33.64 & 24.98 & 66.94 & 60.06 & 0.2024 & 0.071 & 33.90 & 24.27 & 65.94 & 58.71 & 0.2434 \\
\hline 78 & 36.64 & 26.24 & 71.62 & 63.55 & 0.2109 & 0.063 & 37.11 & 27.39 & 73.26 & 65.86 & 0.2424 \\
\hline 80 & 37.42 & 28.63 & 75.59 & 68.43 & 0.1952 & 0.060 & 37.98 & 28.60 & 75.72 & 68.49 & 0.2417 \\
\hline
\end{tabular}

$\mathrm{K}_{\mathrm{bc}} / \mathrm{K}_{\mathrm{e}}$ approach those of the ring diameter and of the ratio $\mathrm{K}_{\mathrm{bc}} / \mathrm{K}_{\mathrm{e}}$ of tellurite based glasses as observed by ElMallawany ${ }^{[13]}$.

The value of $\mathrm{K}_{\mathrm{bc}} / \mathrm{K}_{\mathrm{e}}$ for borotellurite glass system decreases from 2.84 to 2.19 with increasing tellurium dioxide. Table 2 shows that the ratio $\mathrm{K}_{\mathrm{bc}} / \mathrm{K}_{\mathrm{e}}$ decreases with decreasing atomic ring size of the network. This value is attributed to less open three dimensional structure of this glass system. The small value of $\mathrm{K}_{\mathrm{bc}} / \mathrm{K}_{\mathrm{e}}$ (2.19) is attributed to the very close (ring size $=0.5376$ $\mathrm{nm}$ ) three dimensional structure at composition $\mathrm{x}=80$ mol\%. The behaviour of the studied glass is in the same range as reported by El-Mallawany ${ }^{[13]}$ and ElMoneim $^{[12]}$. The increase in the average cross-link density results in an increase in the glass transition temperature, thus the structure will be more compact and cross-link so that the elastic moduli increase and both average ring size and the ratio $\mathrm{K}_{\mathrm{bc}} / \mathrm{K}_{\mathrm{e}}$ decreases $^{[5,10]}$.

The calculated and experimental Poisson's ratio is tabulated in Table 3. For this borotellurite glass system, there are some modifications made on $\sigma_{\text {cal }}$ and $\mathrm{K}_{\text {cal }}$ relation to fit for the studied glass system. The $\sigma_{\mathrm{cal}}$ relation is

$$
\sigma_{\text {cal }}=0.414\left(\overline{\mathrm{n}_{\mathrm{c}}}\right)^{-1.4508}
$$

and for $\mathrm{K}_{\text {cal }}$ is

$$
\mathrm{K}_{\text {cal }} \mathrm{V}_{\text {cal }}=1.2 \times 10^{-27} \overline{\mathrm{F}}^{2} l^{-1.3535}
$$

It is known that Poisson's ratio is affected by the changes in the cross-link density of the glass network. Rajendran et al.$^{[3,14]}$ and Bridge et al. ${ }^{[15-17]}$ proposed that a high cross-link density has Poisson's ratio in the order of 0.1-0.2, while a low cross-link density has Poisson's

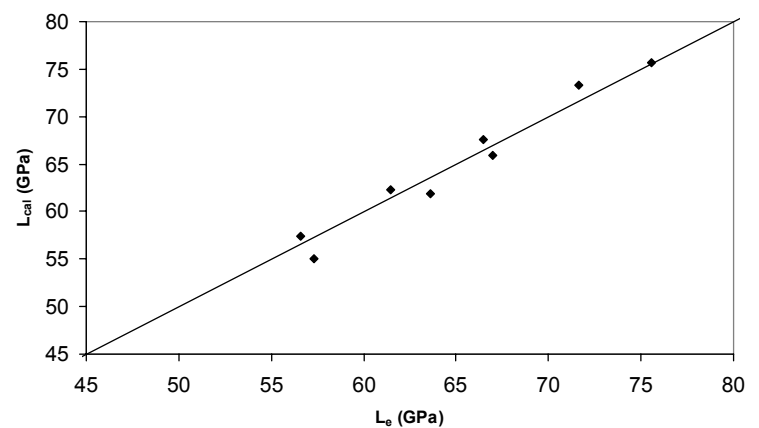

Fig. 7: Correlation between calculated and experimental longitudinal modulus for $\left(\mathrm{TeO}_{2}\right)_{\mathbf{x}}\left(\mathrm{B}_{2} \mathrm{O}_{3}\right)_{1-\mathrm{x}}$ glass system

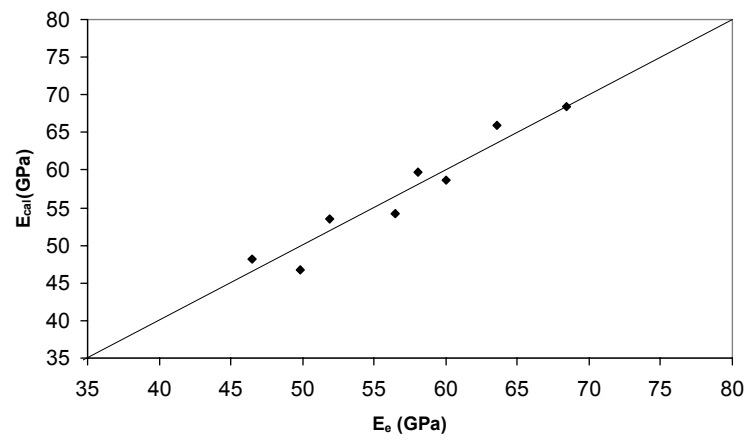

Fig. 8: Correlation between calculated and experimental Young's modulus for $\left(\mathrm{TeO}_{2}\right)_{\mathrm{x}}\left(\mathrm{B}_{2} \mathrm{O}_{3}\right)_{1-\mathrm{x}}$ glass system

ratio between 0.3 and 0.5 . In the studied glass, Poisson's ratio decreases $(0.2576$ to 0.1952 for experimental Poisson's ratio and 0.2489 to 0.2417 for calculated Poisson's ratio) with increasing cross-link 
density (changes from 1.43 to 1.67 ) when $\mathrm{TeO}_{2}$ content is increased. This supports that bridging oxygen have been created which will strengthen the glass network. Moreover, these cross-links generate strong covalent forces to resist lateral contraction and consequently decrease the Poisson's ratio values ${ }^{[8]}$.

The activation energy depends on the value of the cation-anion forces. For a given A-O-A bond angle the A-A separation would directly proportional to the stretching force constant of the network ${ }^{[9]}$. The A-O-A bond force constant decreases, the energy required will decrease to produce a given degree of bond angle or length distortion which leads to a decrease in activation energy. The average stretching force constant $\mathrm{F}$ for the studied glass decreases from $364.00 \mathrm{~N} / \mathrm{m}$ to $286.11 \mathrm{~N} / \mathrm{m}$ and the activation energy decreases from $0.099 \mathrm{eV}$ to $0.060 \mathrm{eV}$. Results indicate the connectivity and hence rigidity of this glass system increases with increasing $\mathrm{TeO}_{2}$ content.

Table 3 shows the calculated and experimental value of elastic moduli for $\left(\mathrm{TeO}_{2}\right)_{\mathrm{x}}\left(\mathrm{B}_{2} \mathrm{O}_{3}\right)_{1-\mathrm{x}}$ glass. The values of experimental elastic moduli have been taken from elsewhere ${ }^{[7]}$. The calculated elastic moduli (shear $\mathrm{G}_{\text {cal }}$, longitudinal $\mathrm{L}_{\text {cal }}$, bulk $\mathrm{K}_{\text {cal }}$ and Young's $\mathrm{E}_{\text {cal }}$ ) are in the range of the experimental values. Figure 5-8 show the agreement between the theoretical calculated values of bulk, shear, longitudinal and Young's elastic modulus respectively. The straight line in each figure has a gradient of unity. The figures show that the correlation coefficient between the calculated and the corresponding experimental values changes between $96 \%$ to $100 \%$ for bulk modulus, between $94 \%$ to $100 \%$ for Young's modulus, between $96 \%$ to $100 \%$ for longitudinal modulus and between $93 \%$ to $100 \%$ for shear modulus. It is observed that by using Equations (15) and (16), it can be consider that this model gives a good agreement between the calculated and the experimental values of elastic moduli.

\section{CONCLUSION}

The elastic moduli and structure of borotellurite glass $\left(\mathrm{TeO}_{2}\right)_{\mathrm{x}}\left(\mathrm{B}_{2} \mathrm{O}_{3}\right)_{1-\mathrm{x}}$ has been studied as a function composition by calculating the number of network bonds per unit volume, the average cross-link density, activation energy, bond compression bulk modulus and Poisson's ratio. The agreement between the theoretically calculated and experimental elastic moduli is excellent for the studied samples.

\section{ACKNOWLEDGEMENT}

The financial support of the Ministry of Science, Technology and Innovation, Malaysia under IRPA vote 54061 is gratefully acknowledged.

\section{REFERENCES}

1. El-Mallawany, R., 2002. Tellurite Glasses Handbook. Physical Properties and Data, CRC Press, pp: 540.
2. El-Mallawany, R., N. El-Khoshkhany and H. Afifi, 2006. Ultrasonic studies of $\left(\mathrm{TeO}_{2}\right)_{50}-\left(\mathrm{V}_{2} \mathrm{O}_{5}\right)_{50}$ ${ }_{x}\left(\mathrm{TiO}_{2}\right)_{\mathrm{x}}$ glasses. Mater. Chem. Phys., 95: 321-327.

3. Rajendran, V., N. Palanivelu, B.K. Chaudhuri and K. Goswami, 2003. Characterisation of semiconducting $\mathrm{V}_{2} \mathrm{O}_{5}-\mathrm{BiO}_{3}-\mathrm{TeO}_{2}$ glasses through ultrasonic measurements. J. Non-Cryst. Solids, 320: 195-209.

4. Saddeek, Y.B., 2004. Ultrasonic study and physical properties of some borate glass. Mater. Chem. Phys., 83: 222-228.

5. Saddeek, Y.B., 2005. Elastic properties of $\mathrm{Gd}^{3+}-$ doped tellurovanadate glasses using pulse-echo technique. Mater. Chem. Phys., 91: 146-153.

6. Chowdari, B.V.R. and P. Pramoda Kumari, 1998. Studies on $\mathrm{Ag}_{2} \mathrm{O} . \mathrm{M}_{\mathrm{x}} \mathrm{O}_{\mathrm{y}} \mathrm{TeO}_{2}\left(\mathrm{M}_{\mathrm{x}} \mathrm{O}_{\mathrm{y}}=\mathrm{WO}_{3}, \mathrm{MoO}_{3}\right.$, $\mathrm{P}_{2} \mathrm{O}_{5}$ and $\mathrm{B}_{2} \mathrm{O}_{3}$ ) ionic conducting glasses. Solid State Ionics, 113-115: 665-675.

7. Halimah, M.K., H.A.A. Sidek, W.M. Daud, H. Zainul, Z.A. Talib, A.W. Zaidan, A.S. Zainal and H. Mansor, 2005. Ultrasonis study and physical properties of borotellurite glass. Am. J. Appl. Sci., 2: 1541-1546.

8. Bridge, B., N.D. Patel and D.N. Waters, 1983. Elastic constants and structure of the vitreous system. Phys. Stat. Sol., 7: 655-666.

9. Higazy, A. and B. Bridge, 1985. Elastic constants and structure of the vitreous system $\mathrm{Co}_{3} \mathrm{O}_{4}-\mathrm{P}_{2} \mathrm{O}_{4}$. J. Non-Cryst. Solids, 72: 81-108.

10. El-Mallawany, R., 2000. Structural interpretations on tellurite glasses. Mater. Chem. Phys., 63: 109115.

11. Bridge, B. and N. Patel, 1986. Ultrasonic relaxation studies of the vitreous system Mo-P-O. J. Mater. Sci., 21: 3783-3800.

12. El- Moneim, A.A., 2003. Quantitatively analysis of elastic moduli and structure of $\mathrm{B}_{2} \mathrm{O}_{3}-\mathrm{SiO}_{2}$ and $\mathrm{Na}_{2} \mathrm{O}-\mathrm{B}_{2} \mathrm{O}_{3}-\mathrm{SiO}_{2}$ glasses. Physics B, 325: 319-332.

13. El-Mallawany, R. 1994. Theoretical analysis of ultrasonic wave attenuation and elastic moduli of tellurite glasses. Mat. Chem. Phys., 39: 161-165.

14. Rajendran, V., N. Palanivelu, D.K. Modak and B.K. Chaudhuri, 2000. Ultrasonic investigation on ferroelectric $\mathrm{BaTiO}_{3}$ doped $80 \mathrm{~V}_{2} \mathrm{O}_{5}-20 \mathrm{PbO}$ oxide glasses. Phys. Stat. Sol. A, 180: 467-477.

15. Bridge, B. and A. Higazy, 1985. Elastic constants and structure of the vitreous system $\mathrm{Co}_{3} \mathrm{O}_{4}-\mathrm{P}_{2} \mathrm{O}_{4}$. J. Non-Crystalline Solids, 72: 81-108.

16. Bridge, B. and A. Higazy, 1986. Ultrasonic relaxation studies of the vitreous system Mo-P-O in the temperature range 4 to $300 \mathrm{~K}$. J. Mater. Sci., 20: 3783-3800.

17. Bridge, B., 1989. A model for estimating the bulk modulus of polycomponent inorganic oxide glasses. J. Mater. Sci., 24: 804-810.

18. Wells, A., 1975. Structural Inorganic Chemistry. Oxford: Clarendon Press. 